\title{
$O$ fundamento do direito internacional público: uma releitura da Vereinbarung
}

\section{The Foundation of Public International Law: A Reassessment of the Vereinbarung}

\section{La fondation du droit international public: une relecture du Vereinbarung}

\section{Vinicius Hsu Cleto*}

\begin{abstract}
SUMÁRIO: I. Introdução. II. A miríade de teorias explicativas e a contraposição entre objetivistas e positivistas. III. As críticas ao voluntarismo e ao objetivismo. IV. A Vereinbarung de Triepel: apresentação e resposta às críticas. V. Adendos à teoria da vontade coletiva dos Estados. VI. A vontade coletiva aplicada: $\mathrm{ONU}$ como exemplo. VII. A vontade coletiva aplicada: o caso do Tribunal Penal Internacional. VIII. Conclusão. IX. Referências bibliográficas.
\end{abstract}

* Fundação de Estudos Sociais do Paraná, Brasil; ORCID ID: https: / / orcid.org/0000-00023801-8981; viniciushsu@hotmail.com.

Artículo recibido el 13 de febrero de 2020

Aprobado para publicación el 9 de octubre de 2020 
Resumo: Discutido por jusfilósofos e internacionalistas, o fundamento de validade do Direito Internacional Público — o motivo pelo qual as normas jusinternacionais são dotadas de cogência legítima - nunca teve consenso entre especialistas. Nota-se, entretanto, tendência contemporânea a favorecer as narrativas Objetivistas, que apontariam fundamento de validade suprapositivo, para além da vontade estatal. Este artigo defende a retomada da Vereinbarung, ou seja, a Vontade Coletiva dos Estados, como única narrativa capaz de sustentar a obrigatoriedade legítima das normas de Direito Internacional, ressalvados adendos à teorização original.

Palavras-chave: fundamento do direito internacional público, voluntarismo, Triepel.

ABSTRACT: The source of validity of Public International Law - the reason why international norms are legitimate and mandatory — has been discussed by philosophers and internationalists with no reachable consensus. Nonetheless, there is a contemporary tendency towards favoring Objectivist narratives, which believe that any source is suprapositive, beyond State will. This article defends Vereinbarung, in other words, the Collective Will of States, as the only narrative able to support the legitimate obligatoriness of Public International Law norms, regardless of necessary amendments.

Key words: foundation of international law, voluntarism, Triepel.

RÉSUMÉ: Le fondement du Droit International Public — la raison pour laquelle les normes sont légitimes et obligatoires - a été discuté par des philosophes et par des internationalistes sans possible consensus. Néanmoins, il y a une certaine tendance contemporaine qui privilégie des récits Objectivistes, c'est-à-dire, qui souligne des raisons suprapositives, au-delà de la volonté des Etats. Cet article défend la Vereinbarung, la Volonté Commune des Etats comme le seul récit capable d'expliquer la légitimité des obligations du Droit International Public, malgré quelques nécessaires réparations.

Mots-clés: fondement du droit international, volontarisme, Triepel. 


\section{INTRODUÇÃO}

O fundamento das normas de Direito Internacional Público (DIP) é tópico tradicionalmente cuidado pelos estudiosos do ramo. No entanto, com a ascensão das explicações naturalistas, ordinariamente fluidas e abstratas, abriuse margem para que múltiplas narrativas ganhassem terreno, o que agravou a inconclusão que paira sobre o assunto. Enquanto as diversas correntes do Voluntarismo se fixavam sobre a maneira pela qual a vontade estatal criava normas jurídicas internacionais, o Objetivismo ou Naturalismo abriu a caixa de Pandora da especulação etérea. Certos valores internacionais compartilhados poderiam ser a causa primeira da cogência das normas, sem muito se perquirir quais seriam tais valores. Ainda, apontou-se o necessário convívio internacional como fator de obrigatoriedade de certos mandamentos jurídicos. Outra corrente doutrinária buscou Direitos Fundamentais dos Estados, anteriores ao Direito entre nações. A indefinição doutrinária, inquietante para o pesquisador, deu-se precipuamente pela perda de um elemento comum às narrativas, tal como é a vontade para os Voluntaristas. Estes teóricos, respeitadas diferenças a serem esmiuçadas, foram atacados pelas supostas desconsiderações sobre o ideal de Justiça, pelo apego ao formalismo, pelo estadocentrismo e, mais recentemente, pela consolidação das normas imperativas de Direito Internacional Geral, as normas jus cogens, apresentadas no artigo 53 da Convenção de Viena sobre Direito dos Tratados entre Estados (1969). Estas normas não poderiam ser revogadas pelo protesto unilateral de Estado, tampouco por acordos internacionais voluntários que não envolvessem a comunidade internacional como um todo.

Essas considerações enterraram precocemente o Voluntarismo e, com ele, a Teoria da Vontade Coletiva dos Estados, a Vereinbarung proposta por Karl Heinrich Triepel. Ao longo do artigo, pretende-se sumarizar, brevemente, a disputa entre Objetivistas e Voluntaristas, bem como apresentar, com adendos, a teorização do professor de Leipzig, refutadas, argumentativamente, críticas que lhe foram dirigidas. No mesmo sentido, são expostas apreciações que buscam problematizar as demais correntes doutrinárias.

O estudo se baseia em análise bibliográfica temática, bem como na investigação da estrutura orgânica e modus operandi da Organização das Nações Unidas (ONU) e do Tribunal Penal Internacional (TPI). 


\section{A MIRÍADE DE TEORIAS EXPLICATIVAS E A CONTRAPOSIÇÃO}

ENTRE OBJETIVISTAS E POSITIVISTAS

Inicialmente, a busca do fundamento de obrigatoriedade do Direito Internacional Público se prestou a espancar questionamentos sobre a juridicidade dessas normas. Sem fundamento, o conjunto de prescrições consubstanciaria o infame soft law, recomendações de condutas que, se inobservadas, nada representariam, ressalvada a violação de algum dever moral: "Entre los imprescindibles negadores del derecho internacional público, se encuentran Jack L. Goldsmith y Eric A. Posner. Para ellos, el DIP no es más que un instrumento utilitario a los fines e intereses de los Estados y un vehículo para maximizar intereses y resultados convenientes". ${ }^{1}$

Os negacionistas apontam que o Direito Internacional Público é rotineiramente empregado e interpretado no interesse dos Estados. Sendo a paridade entre eles fictícia, os mais poderosos delineariam as normas de acordo com as próprias crenças. Conquanto ainda goze de certa popularidade, a narrativa é frágil. Não se disputa que Estados nacionais busquem interpretar o Direito da maneira que melhor lhes aprouver, tampouco se discute que Estados militar e economicamente mais poderosos desempenhem papel substantivamente mais relevante na legiferação. Trata-se de decorrência lógica, derivada do fato de que os Estados são os principais legisladores e destinatários das normas internacionais. Ocorre que nenhuma das asserções retira o caráter obrigatório e jurídico de certo conjunto normativo que visa a regrar o relacionamento entre sujeitos de DIP. No Direito Interno - este, pelo menos a princípio, é inquestionavelmente Direito - também conta com normas interpretáveis de acordo com o interesse de turno dominante. Comumente, são legislados diplomas que favorecem setores específicos da sociedade que melhor se articularam, independentemente do interesse comum dos demais membros da comunidade. Nem por isso se assevera ausência de Direito. Por

1 Benavides-Casals, María Angélica, "La constitución del derecho internacional, el sueño de un reducto jurídico occidental”, Revista Colombiana de Derecho Internacional, Bogotá, nova série, ano X, núm. 28, Janeiro-Junho de 2016, pp. 16 e 17. Em tradução livre: "Entre os imprescindíveis negadores do Direito Internacional estão Jack L. Goldsmith e Eric A. Posner. Para eles, o DIP não é mais do que um instrumento utilitário para os fins e interesses dos Estados e um instrumento para maximizar interesses e resultados convenientes". 
Esta revista forma parte del acervo de la Biblioteca Jurídica Virtual del Instituto de Investigaciones Jurídicas de la UNAM

isso, uma segunda linha do negacionismo aponta a ineficácia das normas de DIP para demonstrar sua inexistência. Constantemente, diz-se, violam-se regras e princípios de DIP sem consequências fáticas quaisquer, especialmente nos casos em que o infrator é Estado nacional de envergadura. Este equívoco se pauta em duas crenças básicas. A primeira exige que haja sanção institucionalizada pelo comportamento delituoso. A segunda confunde eficácia com relação de poder. ${ }^{3}$ Embora determinados autores separem Direito e Moral de acordo com a existência ou inexistência de reação externa, ${ }^{4}$ há que se notar que, como regra, a violação do DIP é, sim, acompanhada de sanções. Entretanto, elas são usualmente difusas e sortidas, especialmente se unilaterais, o que não descaracteriza claro exercício de autotutela. Este, por sua vez, nem sempre é capaz de demover o infrator ou garantir devida reparação. Nem por isso se pode assentar ausência de sanção, tal como uma astreinte nem sempre assegura que o alvejado modifique o próprio comportamento.

Afastadas as críticas mais comezinhas, o jusinternacionalismo se polarizou em duas correntes básicas. ${ }^{5} \mathrm{O}$ Voluntarismo concebe o Estado nacional como sujeito primário de DIP, aquele que cria as normas jurídicas internacionais por meio de manifestações de vontade. Contra essa concepção, o Objetivis-

2 Em estudo, Alain Pellet compila os significados emprestados ao termo "sanção" pela doutrina internacionalista. Os negacionistas do DIP aderem à noção de Hart, quem exigia sanção, é dizer, tratamento negativo, capaz de modificar o comportamento do infrator. Cfr. Pellet, Allain e Miron, Alina, "Sanctions", em Wolfrum, R. et al. (coords.), The Max Planck Encyclopedia of Public International Law, vol. IX, Oxford, Oxford University Press, 2012, pp. 1-15.

3 É equívoco igualar "eficácia” a "relação de poder". Enquanto neste caso há efetivo mudança no comportamento alheio, ainda que contra a vontade do sujeito alvejado, na eficácia basta que haja consequência pela violação de norma jurídica.

4 Mello, Celso Duvivier de Albuquerque, Responsabilidade internacional do Estado, Rio de Janeiro, Renovar, 1995, p. 3.

5 "Sin embargo, habremos de distinguir aquí entre estas concepciones dos grandes grupos, a saber: las teorías que fundan la producción normativa consuetudinaria en el «asentimiento» de los Estados — principalmente, el voluntarismo jurídico — y aquellas que invocan una regla superior — y exterior — a las voluntades estatales". Em tradução livre: "Sem embargo, temos que distinguir entre estas concepções dois grupos a saber: as teorias que fundam a produção normativa consuetudinária no assentimento dos Estados — principalmente, o voluntarismo jurídico - e aquelas que invocam uma regra superior - e exterior - às vontades estatais". Toledo Tapia, Fernando Enrique, "Fundamento obligatorio y consentimiento del Estado en la costumbre internacional”, Revista de Derecho, Chile, nova série, ano II, vol. II, núm. 1-2, Dezembro de 1991, pp. 31-59. 
mo ou Naturalismo busca razões diferentes da simples vontade estatal para fundamentar a obrigatoriedade desses comandos. ${ }^{6}$

Stephen Neff separa Positivismo de Voluntarismo, pois aquele conceito abrangeria manifestações doutrinárias diversas, incluído o Voluntarismo:

The first version will be here termed the "empirical" one. It held that the States of the world, acting collectively, functioned as a sovereign, making law through state practice and the formation of customary rules. The second version, here termed the "common-will" approach, held that States, in the process of treaty-making, created a sort of miniature sovereign which commanded adherence to the treaty in question. A third version, here labelled the "voluntarist" one, held each State to be its own sovereign, laying down laws for itself. ${ }^{7}$

No entanto, a nomenclatura deixa a desejar, pois em todas as correntes positivistas se nota a presença da vontade estatal como fundamento de obrigatoriedade, seja em manifestação individual, seja em manifestação coletiva. Não há motivo, portanto, para distinguir o Positivismo jusinternacional do século XIX do Voluntarismo.

Duas linhas teóricas se destacam no que ora se intitula Voluntarismo. Georg Jellinek ("Die rechtliche natur der staatenverträge", "Allgemeine staatslehre") e a Teoria da Autolimitação pretendem que, uma vez soberano, o Estado nacional é o único capaz de legislar para si. Heinrich Triepel ("Völkerrecht und landesrecht") desenvolveu narrativa sofisticada, a ser pormenorizada na sequência, segundo a qual os Estados formariam uma Vontade Coletiva superior capaz de criar direito positivo.

6 Obviamente, a divisão binomial é combatida por autores que concebem alternativas explicativas, como a separação do Normativismo em relação ao Objetivismo ou, então, explicações “mistas" ou "ecléticas”, que mesclam vontade a razões as mais diversas.

7 Neff, Stephenm, "Jurisprudential Polyphony: the Three Variations on the Positivist Theme in the 19th Century", en Dupuy, Pierre-Marie e Chetail, Vincent (coords.), The Roots of International Law: liber amicorum Peter Haggenmacher, Leiden, Martinus Nijhoff, 2014, p. 304. Em tradução livre: "A primeira será denominada «empírica». Ela pretende que os Estados do mundo, agindo coletivamente, funcionam como soberanos, criando Direito derivado da prática estatal e da formação de normas consuetudinárias. A segunda versão, denominada «abordagem da vontade comum», entende que os Estados, no processo de pactuação de tratados, criam uma espécie de «mini soberano» que demanda aderência à convenção. A terceira versão, denominada «voluntarista», compreende que cada Estado é soberano e legisla para si”. 
Esta revista forma parte del acervo de la Biblioteca Jurídica Virtual del Instituto de Investigaciones Jurídicas de la UNAM

Em contraposição ao Voluntarismo, o Objetivismo ou Naturalismo amalgama todos os fatores que são considerados superiores à vontade estatal. Como exposto na introdução, o Objetivismo liquefez a discussão sobre o fundamento de obrigatoriedade das normas internacionais, uma vez que as razões metajurídicas explicativas não mais são conectadas por elemento comum, como a vontade. Assim, foram apontados como fundamentos possíveis i) o Direito Natural, ${ }^{8}$ independentemente do conteúdo dessas normas, ${ }^{9}$ bem como de uma pretensa imutabilidade; ii) a coexistência de Estados soberanos e paritários; ${ }^{10}$ iii) uma norma jurídica superior ${ }^{11}$ aos demais mandamentos do

8 “...la afirmación fundamental: el derecho internacional existe y su fundamento está en el derecho natural”. Em tradução livre: "a afirmação fundamental: o Direito Internacional existe e seu fundamento está no Direito Natural”. Fernández Flores, José Luiz, “El problema de la existencia del derecho internacional”, Revista Española de Derecho Internacional, Madrid, nova série, ano XXII, vol. 22, núm. 1, 1969, pp. 42-60.

9 Note-se que, para Wyler, "A nos yeux en effet, les théories jusnaturalistes modernes, en premier lieu celles de l'Ecole du droit de la nature et des gens, sont des théories volontaristes". Em tradução livre: "A nosso ver, as teorias jusnaturalistas modernas, em primeiro lugar aquelas da Escola do Direito Natural e das Gentes, são teorias voluntaristas". Wyler, Eric, "L'influence du positivisme sur la doctrine volontariste et objectiviste en: plus qu'un facteur de rapprochement?", em Dupuy, Pierre-Marie e Chetail, Vincent (coords.), The Roots of International Law: liber amicorum Peter Haggenmacher, Leiden, Martinus Nijhoff, 2014, p. 337.

10 "Le jeune Verdross fait sienne la doctrine kelsenienne de la norme fondamentale, mais, partageant la conception positiviste de la souveraineté, il la situe au sommet du droit étatique, ce qui a pour consequence que le droit international a pour fondement la constitution des divers Etats". Em tradução livre: "O jovem Verdross se apropria da doutrina kelseniana da norma fundamental, mas, ao adotar a concepção positivista da soberania, ele a situa no topo do direito estatal, o que acarreta por consequência que o direito internacional tenha por fundamento a constituição de diversos Estados". Truyol y Serra, Antonio, "Verdross et la théorie du droit", EJIL, Europe, 1994, p. 56. No mesmo sentido, sustentado argumento similar, cfr. Alcorta, Amancio, Curso de derecho internacional público, t. I, Buenos Aires, Félix Lajouane Editor, 1986, p. 92.

11 "Reconhece-se, portanto, que a validade de cada regra jurídica deve depender em último caso, não de uma vontade, mas de outra regra da qual provém, porque o direito apresenta — como bem observa Kelsen - a «particularidade de regulamentar sua própria criação; uma regra jurídica determina como outra regra será estabelecida; nesse sentido, a segunda depende da primeira. É este vínculo de dependência que une entre si os diferentes elementos de uma ordem jurídica que é seu princípio de unidade»". Verdross, Alfred, “O fundamento do direito internacional”, Revista de Direito Internacional, Brasília, nova série, ano III, vol. 10, núm. 2, 2013, pp. 1-33. 
DIP e, portanto, fundamental; ${ }^{12}$ iv) o Fato Social ${ }^{13}$ e a consequente; v) solidariedade internacional, entre outros pretextos.

O Objetivismo, compreendido como conjunto de teorias insatisfeitas com o Voluntarismo, originou até mesmo certa Teoria Eclética ou Mista, que afirma no fundamento do DIP a junção da vontade estatal com outro fator. ${ }^{14}$

Embora a discussão metajurídica apresente difícil resolução, tendo em conta que o estatuto de "verdade científica" dependeria de consenso intersubjetivo cada vez mais distante, determinadas críticas mereceram maior ou menor abrigo dos doutrinadores. Elas serão apresentadas na sequência, acompanhadas de ilações sobre a justiça ou injustiça das asserções.

\section{AS CRÍTICAS AO VOLUNTARISMO E AO OBJETIVISMO}

A Teoria da Autolimitação foi objeto de críticas pela dificuldade de explanar a cogência do costume internacional, especialmente nos casos em que Estados nacionais recém-criados se viam constrangidos por normas de cuja

12 “Ce droit international général, pour une grande part coutumier du moins à ses origines (notamment pour l'établissement de la règle «pacta sunt servanda»), trouvait son fondement de validité, selon Kelsen dans une «norme fondamentale» formulée ainsi: «les États doivent se conduire comme ils ont accoutumé de se conduire»". Cfr. Halpérin, Jean-Louis, "L’histoire du droit international est-elle compatible avec les théories positivistes?”, em Dupuy, Pierre-Marie e Chetail, Vincent (coords.), The Roots of International Law: liber amicorum Peter Haggenmacher, Leiden, Martinus Nijhoff, 2014, pp. 371 e 372. Em tradução livre: "Este direito internacional geral, em grande parte consuetudinário, pelo menos em suas origens (notadamente no estabelecimento da regra «pacta sunt servanda», encontrava seu fundamento de validade, segundo Kelsen, numa norma fundamental assim formulada: «os Estados devem ser conduzir como estão acostumados a se conduzir»”.

13 O DIP seria necessidade social, nos termos de Scelle, cfr. Wyler, Eric, op. cit., p. 356.

14 "En esta concepción del derecho, el problema del fundamento del derecho internacional no se plantea como una dicotomía... sino, por el contrario, como un difícil problema en el que lo esencial estriba en la necesidad de tomar en consideración tanto el consentimiento de los Estados como lo que no depende de la voluntad de los Estados soberanos". Cfr. Carrillo Salcedo, Juan Antonio, "El fundamento del derecho internacional: algunas reflexiones sobre un problema clásico”, Revista Española de Derecho Internacional, Madrid, nova série, ano L, vol. 50, núm. 1, Janeiro-Junho de 1998, p. 30. Em tradução livre: "Nesta concepção do Direito, o problema do fundamento do Direito internacional não se encontra numa dicotomia... mas, ao contrário, num difícil problema em que o essencial é tomar em consideração tanto o consentimento dos Estados como o que não depende da vontade dos Estados soberanos". 
gênese não vieram a participar. ${ }^{15} \mathrm{O}$ sepultamento definitivo se deu pela codificação do jus cogens, as normas imperativas de Direito Internacional Geral, reguladas no artigo 53 da Convenção de Viena sobre Direito dos Tratados entre Estados (1969). Conquanto inexista catálogo definitivo dessa categoria de normas jurídicas internacionais, elas não podem ser revogadas pela vontade singular do Estado: nisso, a título de ilustração, o DIP contemporâneo proscreve o restabelecimento da escravidão e do tráfico de escravos, independentemente do que se estabeleça em Direito Interno ou em tratados internacionais parciais.

Triepel e a Teoria da Vontade Coletiva dos Estados não passaram incólumes. Faltaria à Vereinbarung o sujeito capaz de exercer a Vontade Coletiva. Não suficiente, o professor de Leipzig se recusava, segundo interpretação crítica, a aceitar que Estados não participantes da Vontade Coletiva pudessem ser obrigados pelas normas jurídicas derivadas desse feixe volitivo: “De esta forma, para Triepel, no pueden existir costumbres que obliguen a Estados que no han prestado su acuerdo para su formación". ${ }^{16}$

Ainda, em termos históricos, nota-se abandono do Voluntarismo em favor do Objetivismo por conta dos morticínios perpetrados durante as guerras mundiais, que denunciaram a arbitrariedade estatal ${ }^{17}$ que a narrativa voluntarista poderia embasar:

Grewe devoted considerable attention to the "sources" of international law. For example, he traced the decline of natural conceptions and the rise of consent-based positivist approaches from the 15th century through to the early 20th century. He then described the subsequent turn towards a secular natural law and a "frenzy" of codification during the years following the First and Second World Wars. ${ }^{18}$

15 Certas Teorias do Consentimento Tácito vieram ao socorro da Autolimitação, mas foram fulminadas pelo jus cogens.

16 Toledo Tapia, Fernando Enrique, op. cit., pp. 31-59.

17 Carrillo Salcedo celebra a noção de jus cogens como meio de se evitar que qualquer ato, até mesmo o mais imoral, pudesse receber guarnição jurídica. Cfr. Carrillo Salcedo, Juan Antonio, op. cit., p. 15.

18 Em tradução livre: "Grewe devotou atenção considerável às «fontes» do direito internacional. Por exemplo, ele traçou o declínio das concepções naturais e a ascensão das abordagens positivistas baseadas no consentimento desde o século XV até o limiar do século XX. Ele então descreveu uma guinada em direção a direito natural secular e um «frenesi» de codificação durante os anos posteriores à Primeira e à Segunda Guerras Mundiais". Byers, Michael, "The Shifting Foundations of International Law: a Decade of Forceful Measures against Iraq”, European Journal of International Law, Europa, nova série, ano XIII, vol. 13, núm. 1, 2002, p. 22. 
A resposta ao Voluntarismo não foi, entretanto, satisfatória. Por outro lado, o Objetivismo que vislumbra nos Direitos Naturais (ou Direitos Fundamentais do Estado, numa variante) o fundamento de obrigatoriedade não explica a origem desses direitos, nem por qual razão o conteúdo deles varia no tempo e no espaço. ${ }^{19}$ Se esse jusnaturalismo é baseado na "consciência humana" da época ou na psique dos representantes das comunidades, pois, em verdade, o Direito daí derivado tão somente existe a partir de atos materiais que concretizem a vontade. Inexiste norma jurídica que nasça do mero sentimento de correição; ele deve ser concretizado mediante tratados internacionais, especialmente os multilaterais ou, ao menos, mediante a conduta que se pretende costume internacional. Do contrário, não se separa Direito de Moral. Em síntese, a vontade de criar obrigações jurídicas imputáveis seria o nascedouro do DIP. O senso de justiça é insuficiente para originar normas jurídicas, pois reside no íntimo individual, ainda que compartilhado. Apenas com a vontade de se proteger determinado conjunto de valores elevados é que se pode criar dever externo que supere o âmbito egoístico, esfera em que os valores são resguardados por eventuais amarras morais individuais.

Outra corrente popularizada, corolário do adágio ubi societas, ibi jus, entende que o mero convívio de Estados soberanos acarreta a existência de normas reguladoras das inter-relações, comandos necessários e, portanto, jurídicos. Esta narrativa confunde finalidade e fundamento do Direito. É certo que as normas jurídicas se prestam a regular inter-relações gerais, interna ou internacionalmente. Está-se diante da finalidade do Direito. Sem embargo, não se pode asseverar, com base nessa constatação, que determinado conjunto de normas é legítimo e vinculante.

Certamente, a coexistência de entidades soberanas demanda normas de convivência, uma vez que a vontade unilateral não seria passível de imposição. Todavia, é possível que haja sociedade internacional composta por Estados comandados por burocratas ilustrados, guiados por normas recomen-

19 "Reforçando essa ideia contrária à tese universalista dos direitos humanos, existe a constatação empírica de que há uma grande diversidade de valores morais e de sistemas jurídicos pautados em pluralidade cultural que expressa imensa multiplicidade cultural —o que se tornou um imbróglio na sedimentação da perspectiva universalista dos direitos humanos". Araújo, Jailton Macena de, "Direitos Humanos e solidariedade — entre o universalismo e o relativismo, por uma teoria dialógica dos Direitos Humanos”, Revista de Informação Legislativa, Brasília, nova série, ano LIII, vol. 53, núm. 212, Outubro-Dezembro de 2016, p. 158. 
datórias, convencionadas ou não — e este estado de coisas cada vez mais se aproxima da realidade: "Loin de diminuer au plan international, le phénomène de la soft law s'intensifie au contraire depuis une trentaine d'années" ${ }^{20} \mathrm{O}$ soft law não autoriza Estado prejudicado pela violação da recomendação a buscar autotutela (self-help) ou a ajuizar ações em tribunais internacionais. Inexistente responsabilidade internacional, igualmente inexistentes as normas jurídicas internacionais. Nem concepção ampla do Direito, que abarque a categoria das recomendações, seria capaz de resgatar a Teoria da Necessidade do Direito como fundamento, pois esta demanda, conceitualmente, a causa profunda da obrigatoriedade das normas - e sua consequente indisponibilidade.

Não haveria, no entanto, certos Direitos Fundamentais do Estado, independentes da vontade, emanações típicas derivadas da constituição do sujeito originário de DIP? Direitos Fundamentais que, uma vez estabelecidos pela mera conjunção de território, população permanente, governo efetivo e soberano, seriam a origem de todos os demais direitos e deveres internacionais, até mesmo daqueles dirigidos especificamente à pessoa humana? Indubitavelmente, o DIP contemporâneo consolidou a Teoria Declaratória do reconhecimento dos Estados. Todo Estado recém-criado teria, no patrimônio jurídico, o direito mínimo à integridade territorial, independentemente do reconhecimento alheio. A teoria dos Direitos Fundamentais do Estado não explica, entretanto, a origem da norma —legítima, vinculante e, portanto, jurídica - que protege a integridade soberana. Tampouco justifica a pré-existência de quaisquer outras normas jurídicas consideradas "fundamentais". Estas só podem existir, com efeito, se positivadas pela vontade dos sujeitos primários de DIP, único elemento apto a transmitir, no plano do dever-ser, sentimento íntimo de obrigatoriedade. Curiosamente, o jus cogens se presta também a combater esta teorização. Posto que a integridade soberana seja direito típico do Estado nas relações internacionais, a depender das condutas adotadas internamente, um ente coletivo denominado Organização das Nações Unidas, mediante órgão executivo rotulado Conselho de Segurança, poderia se valer de meios logísticos ou militares direcionados

20 Em tradução livre: "Longe de arrefecer no plano internacional, o fenômeno do soft law, ao reverso, se intensifica há uns trinta anos". Duplessis, Isabelle, "Le vertige et la soft law: réactions doctrinales en droit international”, Revue Québécoise de Droit International, Québec, 2007, pp. 245-268. 
contra a autonomia do Estado individual, bastando que se vislumbre ameaça à paz ou à segurança internacionais. Por outro lado, os defensores da teoria poderiam arguir que esses direitos fundamentais do Estado não são absolutos. No entanto, se não são absolutos, quem determina a relatividade deles? Trata-se de ofensa à noção de que o Estado, sujeito originário de DIP, é soberanamente igual aos demais.

Outra narrativa doutrinária de peso é atribuída ao jusfilósofo austríaco Hans Kelsen. Transplantada a teoria da Grundnorm do Direito Interno para o DIP, haveria norma pressuposta que exigiria observância dos comandos jurídicos internacionais. Kelsen foi quem melhor justificou o Direito estatal doméstico contemporâneo: se grupo revolucionário exitoso é capaz de centralizar a atividade legislativa, acompanhada de consequências sancionatórias pela desobediência, sem que haja grupos conflitantes fortes o suficiente para solapar o domínio daquela autoridade, está-se diante de uma nova ordem normativa. ${ }^{21}$ No plano jurídico internacional.

Como consequência, um Estado, em vez de ser, juntamente com outros Estados, o criador do direito internacional, deste último é a criatura, sendo efetivamente definido como um ordenamento jurídico parcial derivado do direito internacional, ou até mesmo como órgão da comunidade jurídica internacional. ${ }^{22}$

No entanto, se a Grundnorm é aferível com a consolidação de grupo revolucionário apto a controlar parcela de território, no âmbito interestatal a norma pressuposta ${ }^{23}$ necessita, em verdade, de positivação por parte dos Estados nacionais. Ela, por sua vez, ocorrerá a partir de manifestações de vontade dos sujeitos primários de DIP. Quando se exige que "tratados pactuados devam ser respeitados" ou que "os Estados devam observar as condutas reiteradas", essas normas jurídicas dependem da vontade estatal para que haja validade, eficácia e, especialmente, cominação sancionatória pela violação de preceitos. Em outras palavras, a norma que comanda observância do DIP é antecedida pela vontade estatal, invariavelmente.

21 O Estado tem como base a Constituição; os atos de coerção estão embasados em conteúdo e forma em consonância com a Constituição. A validade do ato constituinte, por sua vez, é garantida pela Norma Fundamental. Cfr. Kelsen, Hans, Teoria pura do direito, 8a. ed., São Paulo, WMF Martins Fontes, 2009, p. 8.

22 Kelsen, Hans e Campagnolo, Umberto, Direito internacional e Estado soberano, São Paulo, Martins Fontes, 2002, p. 82.

23 Um comando pretensamente metajurídico que exige que o DIP seja observado. 
Por fim, as Teorias Mistas e Ecléticas são mais um sintoma da derrocada do Voluntarismo do que propriamente uma alternativa explicativa. A vontade é considerada elemento essencial; contudo, se há tantos outros fundamentos de igual relevo, falta à teorização eclética expor qual seria a causa primeira da obrigatoriedade de normas jurídicas internacionais.

\section{A VEREINBARUNG DETRIEPEL: APRESENTAÇÃO E RESPOSTA ÀS CRÍTICAS}

Não se questiona que a existência e o bem-estar da pessoa humana são a finalidade última do Direito, como é, aliás, qualquer outra criação civilizatória. Nem por isso se pode afirmar que a pessoa humana é sujeito primário e originário do DIP, sob pena de não se observar o que é empiricamente atestável. Contemporaneamente, o Direito é criação estatal; as considerações sobre personalidade invariavelmente remetem à legiferação gestada nos Estados nacionais, internamente ou internacionalmente. Se a personalidade internacional da pessoa humana é aceitável por conta da existência de justiça penal supraestatal, que reclama o acatamento de deveres internacionais, nota-se que os deveres bem como os órgãos supranacionais foram criados pela vontade dos Estados.

É a vontade de criar obrigações jurídicas supraestatais que origina o DIP, não a existência de valores compartilhados ou a consciência da utilidade do Direito. O sentimento, per se, é íntimo. Sem a vontade de criar conduta obrigatória - por meio de pactos ou de atividade rotineira - não há Direito. Sem a vontade de proteger normativamente os valores relevantes, não há mandamento externo, geral e abstrato.

Se, entretanto, a Autolimitação satisfaz a igualdade soberana estatal, toda obrigação jurídica internacional poderia ser desfeita pelo capricho do Estado que anteriormente havia assumido dever. A inovação comportamental não seria subsumível a mecanismos clássicos de responsabilidade internacional. As normas imperativas de Direito Internacional Geral, inderrogáveis pela vontade estatal unilateral, seriam inaceitáveis.

Claramente, a vontade estatal que cria o DIP, especialmente os princípios basilares, encontra-se acima do Estado individualmente considerado. Tratase da Vontade Coletiva. 
A Vereinbarung de Triepel reconhece que o fundamento do DIP é elemento extrajurídico, ${ }^{24} \mathrm{o}$ que não poderia ser diferente, dado que é a raiz que possibilita a gênese das normas jurídicas. A Teoria da Vontade Coletiva entende que o fundamento do DIP é o feixe de vontades dos Estados. Textualmente, Triepel não exigia unanimidade entre todos os Estados nacionais:

Só pode ser fonte de direito internacional uma vontade comum, de vários, ou de numerosos, Estados. Consideramos como meio de constituir tal unidade de vontades a "Vereinbarung", termo de que se utiliza a doutrina alemã para designar as verdadeiras uniões de vontades, e as distinguir dos contratos, que são, em nossa opinião, acordos de várias pessoas para declarações de vontades de conteúdos opostos. Encontramos essa "Vereinbarung" nos tratados pelos quais vários Estados adotam uma regra que deve reger sua conduta de modo permanente... Pouco importa que esses tratados sejam concluídos entre grande número de Estados, como, por exemplo, a Convenção de Genebra, o Ato do Congo, o Ato antiescravista, a Declaração de Paris sobre direito marítimo, as Convenções de Haia, e muitos outros; ou que eles sejam concluídos entre dois, ou três, Estados, contanto que contenham regras jurídicas, isto é, direito objetivo. ${ }^{25}$

A Vontade Coletiva, segundo Triepel, cria Direito Objetivo, tratados-leis que não se confundem com os tratados-contratos. Conquanto a teoria não seja isenta de críticas procedentes, a serem desenvolvidas na seção seguinte, ela está, de maneira global, correta. Na concepção do Direito Internacional, todos os Estados, tácita ou expressamente, acordam normas precipuamente genéricas, mas basilares para o DIP. O exemplo mais clássico seria o pacta sunt servanda: todo Estado nacional tem interesse que o acordado seja cumprido. Não é tecnicamente correto, porém, acreditar em mera conjunção de

24 "For this reason, certain jurists, such as Triepel, have urged that the ultimate foundation of any system of law must always lie in some non-juristic field. This point is, in a sense, elementary - yet it is so important to the whole subject that it must be insisted upon”. Em tradução livre: "Por esta razão, alguns juristas, como Triepel, asseveraram que a fundação última de qualquer sistema de direito deve subsistir em algum campo não jurídico. Este ponto, é, em certo aspecto, elementar — mas ainda assim tão importante para a matéria como um todo que deve ser ressaltado". Fitzmaurice, Gerald, "Foundations of the Authority of International Law and the Problem of Enforcement", The Modern Law Review, Londres, nova série, ano XX, vol. 19, núm. 1, Janeiro de 1956, p. 11.

25 Triepel, Karl Heinrich, "As relações entre o direito interno e o direito internacional”, Revista da Faculdade de Direito, Belo Horizonte, nova série, ano LXIII, núm. 6, 1966, p. 15. 
vontades individuais. A Vontade Coletiva que fundamenta o DIP se destaca das vontades singulares iniciais. Se, na sequência, Estado que se beneficia da observância dos acordos internacionais resolve descumprir o disposto nos tratados por motivos egoísticos, viola o DIP porque se insurge contra norma internacional gestada pela Vereinbarung. Nesse aspecto, nota-se clara distinção em relação à Teoria da Autolimitação.

A Teoria da Vontade Coletiva não aniquila a soberania estatal, desde que se compreenda sua correta significação. O predicado da soberania traduz a impossibilidade de Estado criar, unilateral e arbitrariamente, direitos e deveres a seu homólogo. Contudo, se a norma internacional deriva de vontade qualificada, de tal sorte que sujeito de DIP recalcitrante se veja perseguido por contramedidas engendradas por Estados e organizações internacionais (especialmente as de vocação universal), então se nota limite à plena disposição legislativa da soberania individual —consequência lógica da existência mesma do DIP. Esse Direito Objetivo de que trata Triepel apresenta funcionamento similar à Constituição no Direito Interno: os Estados recémcriados, tal como as pessoas naturais recém-nascidas no âmbito doméstico, vinculam-se ao Direito engessado. Não imutável, mas de difícil alteração, como as normas jus cogens.

As normas imperativas de Direito Internacional Geral já foram saudadas como atestado de óbito do Voluntarismo por conta da indisponibilidade unilateral. Sua existência, entretanto, revigora a Vereinbarung. Certas normas internacionais foram positivadas por Vontade Coletiva que apenas poderia ser superada por manifestação de idêntica natureza. Trata-se, com efeito, do conceito codificado pela Convenção de Viena sobre Direito dos Tratados entre Estados de 1969. Se os Estados, ao longo do século XIX, passaram a combater o instituto jurídico da escravidão a ponto de limitarem a soberania reguladora sobre o tópico, nota-se Vontade Coletiva capaz de criar Direito Objetivo que apenas poderia ser superado por manifestação similar. Estados que resistiram à mudança, como o Brasil, passaram a sofrer contramedidas referendadas pela comunidade internacional, especialmente se tendo em conta que aceitação generalizada não exige unanimidade. ${ }^{26}$ As denúncias

\footnotetext{
26 "Pereira e Quadros expressamente afirmam que não é necessário que o Direito imperativo internacional seja aceito por todos os Estados da comunidade internacional, bastando a aceitação generalizada por parte desses Estados”. Viegas, Vera Lúcia, "Ius cogens e o tema da nulidade dos tratados", Revista de Informação Legislativa, Brasília, nova série, ano XXXVI, vol. 36, núm. 144, Outubro-Dezembro de 1999, p. 184.
} 
sobre iniquidades econômicas e militares entre Estados no processo de legiferação do Direito Objetivo não ofendem essa linha de raciocínio. A despeito da importância do debate, assim como no Direito Interno, não se põe em xeque a juridicidade de regras legisladas, ainda que sob forte influência de grupos de pressão que representam interesses elitizados.

Decerto, há questionamentos sobre os mecanismos garantidores e sobre o conteúdo do jus cogens. A problematização poderia comprometer a existência dessas normas imperativas. Para identificá-las, propõe-se exercício hipotético: se impossível contramedida nos mesmos moldes da violação da norma cogente, está-se diante de jus cogens. Cogite-se Estado nacional "A" que, em parceria com Estado nacional "B”, reinstitua o tráfico internacional de escravos. Provavelmente haveria reação de Estados terceiros, bem como da ONU. Seria implausível que os garantidores da ordem jurídica internacional pretendessem escravizar a população dos Estados "A" e "B" como resposta coercitiva. Não surpreenderia, porém, se, em caso de violação de obrigação comercial pactuada em tratado, Estado prejudicado violasse outro dispositivo qualquer em resposta. São essas ilustrações que demonstram a pertinência da diferenciação entre um certo Direito Objetivo, adaptada a categoria do "tratado-lei", e certo Direito Dispositivo, adaptada a categoria do "tratado-contrato".

Claramente, os valores comunitários superiores que sustentam o jus cogens podem mudar ao longo do tempo. A mutação valorativa tem o condão de acionar a Vereinbarung, que alteraria as normas imperativas e inderrogáveis. Como já exposto, nem por isso são os valores comunitários o fundamento do DIP, dado que o sentimento, ainda que espraiado, reside no foro íntimo das pessoas que (re)presentam Estados e organizações internacionais. Não gera, por si só, normas externas legítimas e vinculantes: estas dependem da Vontade Coletiva dos Estados.

Estabelecida a Vereinbarung, questiona-se a necessidade de se aferir um sujeito que a exerça. Se a Vontade Coletiva não se confunde com as vontades individualmente tomadas, seria a comunidade internacional o sujeito responsável por sustentá-la. A noção de comunidade internacional como pessoa internacional apartada não conflita com as teorias da personalidade jurídica já construídas. ${ }^{27}$ Não obstante, qualquer ceticismo remanescente pode ser

27 Veja-se estudo completo em Oliveira, José Lamartine Correa de, Conceito da pessoa jurídica, Curitiba, Universidade Federal do Paraná, 1962. 
enfrentado pelo estabelecimento relativamente exitoso de organização internacional política universal, a Organização das Nações Unidas, como ente capaz de expressar a Vontade Coletiva.

\section{Adendos À TEORIA DA VONTADE COLETIVA DOS ESTADOS}

Literalmente, Triepel entendia que a Vontade Coletiva acarretava o Dualismo na relação entre Direito Interno e DIP: "Se as deduções que acabam de ser feitas forem exatas, delas resulta esta conclusão: o direito internacional público e o direito interno são, não somente partes, ramos, distintos do direito, como também sistemas jurídicos diferentes"28.

O raciocínio do professor de Leipzig se socorre na diferenciação das relações que são regidas. Enquanto o DIP, produto da Vereinbarung, normatiza as relações interestatais, o Direito Interno, naturalmente, não regula o convívio entre Estados soberanos. Constituídos dois sistemas diferentes, o binômio licitude/ilicitude é operado autonomamente em cada um deles. Em outras palavras, o que é ilícito em DIP poderia ser lícito em Direito Interno: o fundamento de cada um dos sistemas seria distinto.

Com a consolidação de normas internacionais dirigidas diretamente à pessoa humana, independentemente de origem nacional e aquiescência estatal, ${ }^{29}$ a teorização se tornou antiquada. Reforça a obsolescência a jurisprudência internacional que considera a atividade legislativa ou judiciária domésticas mero fato internacional suscetível de ensejar responsabilização internacional. Com efeito, se a normativa doméstica acarreta consequências jurídicas supraestatais, ainda que incapazes de modificar o comportamento delituoso interno, não há sustentáculo firme para o Dualismo. Ainda que a Vontade Coletiva seja a raiz do DIP, que, precipuamente, regula relações interestatais, nem por isso o âmbito interno se mantém alheio à normativa jurídica internacional, uma vez que ela define os limites da soberania nacional.

Outro ponto criticável da explanação de Triepel reside na equalização de Direito e Vontade: "O próprio direito é vontade; e não é a vontade humana

28 Triepel, Karl Heinrich, “As relações...”, cit., p. 15.

29 Basta imaginar persecução penal perpetrada pelo Tribunal Penal Internacional contra nacional de Estado não membro desta OI que tenha cometido crime arrolado no Estatuto de Roma no território de Estado membro. 
que cria o direito. A ciência jurídica não é, como a sociologia, ciência que se ocupa do ser, mas ciência do dever". ${ }^{30}$ Contudo, se a Vontade Coletiva fundamenta o DIP, com ele não se confundiria. Deve-se separar a vontade ${ }^{31}$ do produto dela.

Por fim, interpretação da Vereinbarung pretende que "En el orden internacional «es imposible que una regla creada por Vereinbarung obligue a Estados que no han tomado parte en ella». De esta forma, para Triepel, no pueden existir costumbres que obliguen a Estados que no han prestado su acuerdo para su formación". ${ }^{32}$

Em verdade, a Vontade Coletiva, até por não ser necessariamente unânime, poderia vincular Estados que não participaram da constituição desse feixe de vontades. Conforme justificado anteriormente, o DIP Objetivo funciona como uma sorte de Constituição das relações internacionais.

\section{A VONTADE COLETIVA APLICADA: ONU COMO EXEMPLO}

$\mathrm{O}$ advento das organizações internacionais de alcance universal representou marco na discussão do fundamento de obrigatoriedade do DIP. Em termos históricos, já no Tratado de Versalhes (1919), o apartado destinado a regular o Pacto da Sociedade das Nações (SDN) prevê, no artigo 11, que qualquer guerra ou ameaça de guerra interessa à Sociedade como um todo, independentemente de envolver membros da organização internacional. A SDN atribuía a si a função de preservar a paz internacional pelos meios que considerasse adequados, ainda que envolvesse terceiros Estados.

A Organização das Nações Unidas (ONU), cujo marco normativo mais destacado é a Carta de São Francisco (1945), apresenta como propósito a defesa da paz e da segurança internacionais. Para cumprir a missão institucional, faculta-se à ONU o emprego de funções executivas consubstanciadas

30 Triepel, Karl Heinrich, “As relações...”, cit., p. 19.

31 A vontade humana cria o Direito Interno; a vontade estatal cria o DIP. Obviamente, a vontade estatal nada mais é do que a vontade humana legitimada a representar a vontade estatal.

32 Em tradução livre: "Na ordem internacional, «é impossível que uma regra criada por Vereinbarung obrigue a Estados que não tenham tomado parte nela». Desta forma, para Triepel, não podem existir costumes que obriguem Estados que não tenham emprestado sua concordância para sua constituição”. Toledo Tapia, Fernando Enrique, op. cit., pp. 31-59. 
Esta revista forma parte del acervo de la Biblioteca Jurídica Virtual del Instituto de Investigaciones Jurídicas de la UNAM

em constrições econômicas, logísticas e militares, nos termos dos artigos 41 e 42 do tratado mencionado.

A SDN e sua sucessora, a ONU, denotam pessoa jurídica internacional apta a exercer a Vereinbarung. Estudiosos esmiúçam o conteúdo verbal das resoluções mandatórias ${ }^{33}$ do Conselho de Segurança onusiano e notam atividade legislativa que, inclusive, justifica a doutrina contemporânea que arrola atos de organizações internacionais como fonte potencial de DIP.

E, no entanto, nem todos os Estados fazem parte das Nações Unidas. Abandonadas há tempos, as teorias constitutivas do reconhecimento de Estados e governos não se sustentam empiricamente. A ausência de declaração de reconhecimento consubstancia ato descortês que, entretanto, não tem condão para desfazer a conjunção de população permanente, território, governo efetivo e possibilidade de estabelecimento de relações diplomáticas e consulares. Os Estados e governos não reconhecidos podem, ainda assim, padecer das sanções entabuladas pelo Conselho de Segurança da ONU, o que demonstra personalidade jurídica internacional autônoma. Aponta-se - principalmente — que mesmo Estado marginalizado pode vir a ser submetido a resoluções de OI de que não faz parte. A sujeição abstrata seria acompanhada de medidas executivas (enforcement) em caso de infração à Carta da ONU. A interpretação sobre a necessidade de se adotarem medidas coercitivas ocorre no seio de órgão oligopolizado, em que os membros permanentes exercem poder de veto para questões substantivas.

Exemplo ilustrativo sobreveio na Rodésia do Sul, atual Zimbábue. Quando a minoria branca declara, unilateralmente, independência em relação à Grã-Bretanha, o Conselho de Segurança da ONU, mediante a Resolução 216 (1965), ${ }^{34}$ insta os Estados a não reconhecerem a declaração proveniente de minoria racista não representativa da população local. Há dubiedade quanto ao caráter obrigatório dessa Resolução, bem como da subsequente Resolução 217 (1965), ${ }^{35}$ que estimulava os Estados a interromper o fluxo armamentício e econômico com aquele país. Na sequência:

33 Cfr. Alvarez, José E., The Impact of International Organizations on International Law, LeidenBoston, Martinus Nijhoff Publishers, 2017.

34 United Nations, Resolution 216 (1965), Janeiro de 2020. Disponível em: https: / /undocs. $\mathrm{org} / \mathrm{S} / \mathrm{RES} / 216(1965)$.

35 United Nations, Resolution 217 (1965) / [adopted by the Security Council at its 1265th meeting], of 20 November 1965, Janeiro de 2020. Disponível em: https: / /digitallibrary.un.org/ record/90484. 
Em 16 de dezembro de 1966, porém, devido à resistência do regime de Ian Smith, o Conselho decide lançar mão de sua prerrogativa de impor sanções obrigatórias. A Resolução 232 (1966) aplicou sanções seletivas obrigatórias ao comércio com a Rodésia do Sul, tornando-se assim o primeiro exemplo de invocação daquelas medidas por parte das Nações Unidas. O regime, entretanto, já nasce comprometido pela negativa pública da África do Sul, desde o primeiro momento, de dar cumprimento às medidas. Em 29 de maio de 1968, o Conselho, por sua Resolução 253 (1968), determina o embargo total e estabelece comitê encarregado de supervisionar a aplicação do regime. As Resoluções 277 (1970), 388 (1976) e 409 (1977) determinam medidas adicionais de caráter comercial e financeiro. Após a celebração dos acordos de Lancaster House, que previam a independência do Zimbábue sob o controle da maioria negra, o conjunto de sanções foi levantado pela Resolução 460 (1979) de 21 de dezembro de $1979 .^{36}$

As medidas obrigatórias, quando inobservadas, constituem ilícito internacional. Note-se do caso concreto que i) a ONU instou que não se reconhecesse juridicamente governo efetivo de Estado substancialmente independente; ii) a ONU determinou sanções econômicas pela constituição de regime minoritário e racista. As sanções foram impostas independentemente da situação soberana da Rodésia do Sul em defesa de normas internacionais amplamente aplicáveis, entre elas a interpretação extensiva conferida à defesa da segurança internacional.

Pode-se afirmar que a ONU é representativa dos valores internacionais consubstanciados no Preâmbulo e no artigo 1 da Carta de São Francisco; no entanto, esses valores apenas se tornam normas jurídicas ao serem revestidas seja pela prática reiterada, seja pela pactuação dos Estados. Os princípios gerais nada mais são do que costumes mais genéricos e abstratos. Inescapavelmente, a vontade estatal — motor do costume, dos tratados e mesmo dos atos das OI — se faz presente como origem do DIP, tanto que a ONU nasce da confluência de vontades da sólida maioria dos Estados. Não se exige, entretanto, consenso absoluto e imodificável. Do contrário, sequer haveria potenciais violadores de normas internacionais.

A ONU, tal como outras organizações internacionais, nasce de correlação de forças díspares. A ausência de isonomia no processo decisório substantivo do Conselho de Segurança não é fator suficiente, porém, para se afirmar

36 Baumbach, Marcelo, Sanções do Conselho de Segurança: Direito Internacional e prática brasileira, Brasília, FUNAG, 2014, p. 45. 
falta de juridicidade dos comandos canalizados nas resoluções mandatórias. Existe, com efeito, interpretação política determinada precipuamente pelas grandes potências do petit comité. Contudo, semelhante assimetria é ordinária nos Parlamentos nacionais, em que grupos organizados de pressão obtêm êxito em demandas setoriais e corporativistas, sem que haja questionamentos sobre a juridicidade da atividade legislativa. $\mathrm{O}$ fato de haver Vontade Coletiva capaz de limitar o espaço de atuação de Estado individualmente considerado não ofende a soberania: seu limite é determinado pelo DIP. O Estado nacional apenas perderia soberania caso entidade homóloga, independentemente de justificação jurídica supranacional, monopolizasse a condução do governo.

\section{A VONTADE COLETIVA APLICADA: O CASO DO TRIBUNAL PENAL INTERNACIONAL}

Os tribunais internacionais, a diferença dos órgãos judiciais internos, dependem da aquiescência dos litigantes para que haja processamento e decisão sobre lide qualquer. $\mathrm{O}$ sucumbente que vier a desprezar a sentença internacional incorre em novo ilícito internacional, além de justificar as medidas de autotutela (self-help) que possam vir à luz, respeitadas a necessidade e a proporcionalidade.

A gênese de TPI, estável, permanente e institucionalizado, modificou a narrativa geral, conquanto não se trate de tribunal universal. O Estatuto de Roma previu possível caso de condenação internacional por comissão de core crime independentemente do local de ocorrência da infração e independentemente da nacionalidade do infrator. Em outras palavras, a Organização Internacional poderia exercer ius puniendi independentemente: i) da aquiescência de Estado que sustentasse vínculo de nacionalidade com o infrator; ii) do território em que teria ocorrido o crime, desde que sob o regime de remessa (referral):

A título de exemplo, cabe atentar para duas situações nas quais TPI não está autorizado a exercer jurisdição: (i) crimes de guerra cometidos no contexto de uma ocupação militar, em que nem o país ocupante nem o ocupado são membros do TPI; e (ii) crimes contra a humanidade perpetrados dentro das fronteiras de um Estado não parte. Em ambos os casos, o TPI somente poderá atuar se as referidas 
situações forem objeto de remessa pelo Conselho de Segurança. Como se recorda, a ausência de consentimento do "país-alvo" não impede o CSNU de acionar a jurisdição do Tribunal por meio da remessa. Em não havendo intervenção do Conselho, contudo, as áreas permanecem descobertas, à luz das regras constantes do Estatuto que regulamentam o exercício da jurisdição do Tribunal. ${ }^{37}$

Embora os casos sejam isolados e dependam da participação do Conselho de Segurança da ONU, trata-se de amostra de âmbito normativo internacional criado por vontade superior àquela manifestada concretamente por Estado individualizado. Se o principal órgão onusiano pode provocar atuação jurisdicional internacional sem autorização de Estado mediata ou imediatamente envolvido, nota-se existência de Direito Internacional Geral concebido por vontade supraestatal.

Receios sobre atuação abrangente do TPI determinaram protestos unilaterais dos Estados Unidos, membro permanente do Conselho de Segurança da ONU, que se socorreu no artigo 98(2) do Estatuto de Roma. Acordos bilaterais que protegessem agentes estadunidenses foram buscados, ${ }^{38}$ ao arrepio do propósito do tratado internacional.

No entanto, ainda que interpretação restritiva da atuação do TPI impeça maior impacto nas relações internacionais, os tribunais ad hoc da ONU, antecessores desta Corte, são suficientes para fundamentar a Vereinbarung. Os tribunais para a ex-Iugoslávia e para Ruanda cuidaram de crimes internacionais ocorridos em contextos domésticos. Militares e burocratas punidos sofreram julgamento internacional sem prévia delimitação de qual seria a Corte. Apesar das críticas pela pretensa violação do Princípio do Juiz Natural, o DIP acabou por marginalizar a aplicação desse princípio de Direito Interno.

\section{CONCLUSÃO}

O fundamento de obrigatoriedade do DIP é explicado por correntes doutrinárias diversas, virtualmente impossível o consenso entre estudiosos. Esse estado de arte se deve à ascensão do Objetivismo, escola genérica e plurívo-

37 Cardoso, Elio, Tribunal Penal Internacional: conceitos, realidades e implicações para o Brasil, Brasília, Funag, 2012, p. 76.

38 Ibidem, p. 96. 
ca que teria soterrado o Voluntarismo, especialmente após a consagração do ius cogens, as Normas Imperativas de Direito Internacional Geral.

No entanto, a Vontade Coletiva de Triepel, feitas ressalvas interpretativas que não permitem se falar em "nova teoria”, mostra-se a narrativa mais condizente com o grau de institucionalização que o DIP alcançou. Antes mesmo da concepção das organizações internacionais de alcance universal, iniciativas unilaterais e plurilaterais reprimiam o comportamento recalcitrante de Estados que infringiam normas representativas de valores caros à comunidade internacional, tal como o Brasil escravocrata em relação à Inglaterra do século XIX. Com a criação da Sociedade das Nações e da Organização das Nações Unidas, a Vontade Coletiva passou a ser manifestada por sujeitos específicos, originados de tratados internacionais, vencida possível resistência teórica que não vislumbrasse "comunidade internacional” pretérita capaz de exercer a Vereinbarung. Os tribunais penais ad hoc e o TPI reforçaram a proteção de normas concebidas independentemente da aquiescência estatal individual.

Os valores e aspirações de Estados são insuficientes para que haja DIP. Eles residem no âmago dos burocratas que representam essas entidades coletivas. Apenas a vontade estatal —intermediada, obviamente, pela atuação humana - pode criar comandos obrigatórios para sujeitos de DIP. As teorias mistas, muitas vezes desesperadas pela falta de resposta evidente, não esclarecem a questão de fundo, pois apenas pode haver uma raiz primeira.

Nesse emaranhado de elucubrações, o caminho mais apropriado indica que a vontade individual é incapaz de criar e desfazer obrigações, existentes normas imperativas inderrogáveis. Ao mesmo tempo, a vontade é elemento essencial e fundamental, pois o Estado, no DIP contemporâneo, é o sujeito originário que delimita personalidade de outros sujeitos internacionais. Não resta alternativa senão se render à Vontade Coletiva, feixe de vontades que sobreviveria até mesmo ao arrependimento abrupto de algum dos constituintes.

\section{REFERÊNCIAS BIBLIOGRÁFICAS}

Alcorta, Amancio, Curso de derecho internacional público, t. I, Buenos Aires, Félix Lajouane Editor, 1986.

ÁlvarEZ, José E., The Impact of International Organizations on International Law, Leiden-Boston, Martinus Nijhoff Publishers, 2017. 
Araújo, Jailton Macena de, "Direitos Humanos e solidariedade - entre o universalismo e o relativismo, por uma teoria dialógica dos direitos humanos", Revista de Informação Legislativa, Brasília, nova série, ano LIII, vol. 53, núm. 212, Outubro-Dezembro de 2016.

Baumbach, Marcelo, Sanções do Conselho de Segurança: Direito Internacional e prática brasileira, Brasília, FUNAG, 2014.

Benavides-CASAls, María Angélica, "La constitución del derecho internacional, el sueño de un reducto jurídico occidental”, Revista Colombiana de Derecho Internacional, Bogotá, nova série, ano X, núm. 28, Janeiro-Junho de 2016.

BYERS, Michael, "The Shifting Foundations of International Law: A Decade of Forceful Measures against Iraq", European Journal of International Law, nova série, ano XIII, vol. 13, núm. 1, 2002.

Cardoso, Elio, Tribunal Penal Internacional: conceitos, realidades e implicações para o Brasil, Brasília, FUNAG, 2012.

CARrillo SAlCEDO, Juan Antonio, "El fundamento del derecho internacional: algunas reflexiones sobre un problema clásico", Revista Española de Derecho Internacional, Madrid, nova série, ano L, vol. 50, núm. 1, JaneiroJunho de 1998.

DUPLESSIS, Isabelle, "Le vertige et la soft law: réactions doctrinales en droit international”, Revue Québécoise de Droit International, Québec, 2007.

DuPUY, Pierre-Marie e CHETAIL, Vincent (coords.), The Roots of International Law: liber amicorum Peter Haggenmacher, Leiden, Martinus Nijhoff, 2014.

FERNÁNDEZ FLORES, José Luiz, "El problema de la existencia del derecho internacional”, Revista Española de Derecho Internacional, Madrid, nova série, ano XXII, vol. 22, núm. 1, 1969.

Fitzmaurice, Gerald, "The Foundations of the Authority of International Law and the Problem of Enforcement”, The Modern Law Review, Londres, nova série, ano XX, vol. 19, núm. 1, Janeiro de 1956.

HALPÉRIN, Jean-Louis, "L'histoire du droit international est-elle compatible avec les théories positivistes?”, em DuPuY, Pierre-Marie e CHETAIL, Vincent (coords.), The Roots of International Law: liber amicorum Peter Haggenmacher, Leiden, Martinus Nijhoff, 2014.

JELLINEK, Georg, Allgemeine staatslehre, Berlin, O Häring, 1914.

JELLINEK, Georg, Die rechtliche natur der staatenvertrage: ein beitrag zur juristischen construction des völkerrechts, Wien, Alfred Hölder, 1880. 
Kelsen, Hans e Campagnolo, Umberto, Direito internacional e Estado soberano, São Paulo, Martins Fontes, 2002.

Kelsen, Hans, Teoria pura do direito, 8a. ed., São Paulo, WMF Martins Fontes, 2009.

Mello, Celso Duvivier de Albuquerque, Responsabilidade internacional do Estado, Rio de Janeiro, Renovar, 1995.

NEFF, Stephenm, "Jurisprudential Polyphony: the Three Variations on the Positivist Theme in the 19th Century", en DuPuY, Pierre-Marie e CHETAIL, Vincent (coords.), The Roots of International Law: liber amicorum Peter Haggenmacher, Leiden, Martinus Nijhoff, 2014.

OliveIRA, José Lamartine Correa de, Conceito da pessoa jurídica, Curitiba, Universidade Federal do Paraná, 1962.

Pellet, Allain e Miron, Alina, "Sanctions", em Wolfrum, R. et al. (coords.), The Max Planck Encyclopedia of Public International Law, vol. IX, Oxford, Oxford University Press, 2012.

Toledo TAPIA, Fernando Enrique, "Fundamento obligatorio y consentimiento del Estado en la costumbre internacional”, Revista de Derecho, vol. II, núm. 1-2, Dezembro de 1991.

TRIEPEL, Karl Heinrich, "As relações entre o direito interno e o direito internacional”, Revista da Faculdade de Direito, Belo Horizonte, nova série, ano LXIII, núm. 6, 1966.

TRIEPEL, Karl Heinrich, Völkerrecht und landesrecht, Leipzig, C. L. Hirschfeld, 1899.

TRuYOl y SERRA, Antonio, "Verdross et la théorie du droit", EJIL, Europe, 1994.

Verdross, Alfred, "O fundamento do direito internacional”, Revista de Direito Internacional, Brasília, nova série, ano III, vol. 10, núm. 2, 2013.

VIEGAS, Vera Lúcia, "Ius cogens e o tema da nulidade dos tratados", Revista de Informação Legislativa, Brasília, nova série, ano XXXVI, vol. 36, núm. 144, Outubro-Dezembro de 1999.

WYLER, Eric, "L'influence du positivisme sur la doctrine volontariste et objectiviste en droit international: plus quu'n facteur de rapprochement?", em Dupuy, Pierre-Marie e CHETAIL, Vincent (coords.), The Roots of International Law: liber amicorum Peter Haggenmacher, Leiden, Martinus Nijhoff, 2014. 